In a clinic database of workers investigated for OA, 123 workers with $\mathrm{OA}$ and 69 workers without $\mathrm{OA}$ had PEF records containing $>1$ shift pattern with $\geq 4$ days on each shift. The OA definition was based on Oasys-2 score $>2.51$ and the non-OA on an alternative clinical diagnosis and Oasys-2 score $<2.51$. Records not fulfilling the minimum data quantity for the Area Between Curves (ABC) PEF score, or containing respiratory infections, changes in asthma treatment or different exposures on each shift were excluded. The mean $\mathrm{ABC}$ score, mean PEF diurnal variation (DV) on workdays and cross-shift PEF changes were calculated for each shift. The $A B C$ score of the OA workers was lower on nights $(p=0.028)$ and afternoons $(p=0.020)$ compared to day shifts, without significant differences in diurnal variation. There was statistically significant difference between day and night shift cross-shift changes $(p<0.001)$, larger changes being observed in nights. The sensitivity and specificity of the ABC score was $79 \%$ and $99 \%$ for day shifts, $83 \%$ and $98 \%$ for nights and $72 \%$ and $96 \%$ for afternoon shifts. The sensitivity of increased DV on work days compared to rest days was $76 \%$ for day shifts, $78 \%$ for nights and $70 \%$ for afternoons, specificities being $26 \%$, $48 \%$ and $42 \%$, respectively. PEF changes between work and rest show small differences with shift types. The ABC score has high sensitivity and specificity for all three shifts; differences in DV have high sensitivity, but low specificity when using a cut-off point of $>0 \%$ for the difference between work and rest day DV.

\section{S161 REDUCING EXPOSURE TO ALLERGENS IN BAKERIES}

doi:10.1136/thx.2010.150953.12

S J Fraser, H J Mason, A Thorpe, P Roberts, I Smith, G E Evans, J Morton, D Mark. Health and Safety Laboratory, Buxton, Derbyshire, UK

Introduction and Objectives Bakers have one of the highest incidence rates of occupational asthma. This is related to the levels of dust generated in bakeries from both flour itself and 'improvers', which are added to flour to improve the quality of the bread. Bakery improvers can contain known allergens such as fungal alpha amylase, hemicellulase and soya trypsin inhibitor from soya flour, as well as vegetable oil, calcium sulphate and emulsifiers; usually consisting of organic esters and calcium silicate. This study investigated changes to the 'dustiness' of flour by altering the proportions of improvers in the mix, and measured any concomitant reduction in allergen exposure resulting from these changes.

Methods The concentration of calcium sulphate, calcium silicate and vegetable oil were manipulated in a standard improver mix. Both standard 'dustiness' tests and simulation of bakery activities were undertaken. Atmospheric levels of total soluble protein, wheat flour antigen, soya trypsin inhibitor and calcium were measured.

Results The most effective method of decreasing dustiness of improvers and exposure to allergens was to increase the vegetable oil content of the improver. Raising the oil from $2 \%$ to $4 \%$ of the improver mix was associated with a $77 \%$ decrease in airborne wheat flour antigen and soya trypsin inhibitor in the simulation. Reducing the calcium sulphate content reduced the dustiness of the improver, measured by gravimetric analysis. However, the effect on the atmospheric levels of allergens was less clear. Reducing the calcium silicate content within the emulsifier mix was the least effective of the three methods tested.

Conclusions Changing the formulation of the improver represents a simple, practical and inexpensive method of reducing the dustiness and potential exposure to allergens in bakery workers. This study has shown that a small increase in the oil content would be an effective method for reducing bakers' exposure to allergens and dust. However it could affect how easily the improver is blended and so could be subject to limitations. (C) Crown copyright (2010).

\section{S162 JOB CATEGORIES AND RISK OF ADULT ONSET ASTHMA IN THE 1958 BIRTH COHORT FROM AGE 16 TO AGE 42 YEARS}

doi:10.1136/thx.2010.150953.13

${ }^{1} \mathrm{R}$ Ghosh, ${ }^{1} \mathrm{P}$ Cullinan, ${ }^{2} \mathrm{D}$ Strachan, ${ }^{1} \mathrm{D}$ Jarvis. ${ }^{1}$ Imperial College, London, UK; ${ }^{2} \mathrm{St}$. Georges, University of London, London, UK

Introduction Exposures in the workplace may cause adult onset asthma. In this analysis, we present the prevalence of ever working in job categories and the associated risks of adult onset asthma by age 42 in participants in the 1958 birth cohort.

Methods All persons born in the first week of March in Britain in 1958 were recruited into the cohort. By age 429890 cohort members had provided a full occupational history and health information. Job titles and descriptions were initially coded into Standard Occupational Classification 1990 (SOC-90) using a text based computer program. Blind to asthma status we have recoded these jobs into the International Standard Classification of Occupations 1988 (ISCO88) codes. The prevalence of ever working in jobs defined by these codes was determined. Adult onset asthma was defined as reporting 'ever asthma' at ages 33 or 42 and excluding all those who reporting 'ever asthma' at ages 11 or 16 (childhood asthma). The risk of adult onset asthma associated with these job categories was determined in logistic regression analysis adjusted for sex, smoking, region and father's social class at birth. The Simes procedure was used to correct for multiple testing.

Results After excluding childhood asthma the sample consisted of 8358 cohort members with a $9 \%$ prevalence of adult onset asthma. The most common jobs with the greatest risks of adult onset asthma are tabulated.

Conclusion Several job categories were associated with adult onset asthma by age 42 in this cohort of adults born in 1958. This analysis confirms in a British population existing knowledge about occupations associated with the development of asthma in working life, and in particular shows consistent evidence of asthma development in those who have ever worked as a cleaner.

\section{Abstract S162 Table 1}

\begin{tabular}{lllll}
\hline $\begin{array}{l}\text { ISC0-88 } \\
\text { Code }\end{array}$ & Occupation & $\begin{array}{l}\text { Prevalence \% (n) } \\
\text { Total } \mathbf{n = 8 3 5 8}\end{array}$ & OR (crude) & OR (adjusted) \\
\hline 9130 & Cleaners-unspecified & $2.1(176)$ & 1.90 & $1.76(1.12-2.76)$ \\
9131 & Cleaners-domestic & $1.5(124)$ & 1.74 & $1.54(0.90-2.64)$ \\
9132 & Cleaners-hotels & $7.0(585)$ & 1.76 & $1.65(1.24-2.18)$ \\
5122 & Cooks & $4.9(406)$ & 1.61 & $1.55(1.12-2.16)$ \\
5123 & Waiters/bartenders & $9.1(760)$ & 1.47 & $1.38(1.12-2.16)$ \\
5133 & Home-based personal & $5.4(450)$ & 1.85 & $1.67(1.23-2.27)$ \\
& care workers & & & \\
5141 & Hairdressers & $2.9(244)$ & 1.89 & $1.60(1.09-2.36)$ \\
5169 & Protective services workers & $1.8(147)$ & 1.63 & $2.05(1.23-3.43)$ \\
& not elsewhere classified & & & \\
8263 & Sewing-machine operators & $1.8(154)$ & 1.93 & $1.72(1.07-2.77)$ \\
9320 & Labourers & $2.6(216)$ & 1.84 & $2.02(1.34-3.07)$ \\
9322 & Hand packers and other & $2.3(188)$ & 1.60 & $1.48(0.93-2.34)$ \\
& manufacturing labourers & & & \\
\hline
\end{tabular}

Funding This work was funded by Asthma UK, RG PhD funded by the COLT Foundation. 